\title{
Effect of a Porous Structure of the Carbon Sorbents from Abies Wood Lignin on Sorption of the Organic Substances of Different Nature
}

\author{
Evgenia V. Veprikova*, Ivan P. Ivanov, \\ Nikolay V. Chesnokov and Boris N. Kuznetsov \\ Institute of Chemistry and Chemical Technology SB RAS \\ $F R C$ "Krasnoyarsk Scientific Center of the SB RAS" \\ 50/24 Akademgorodok, Krasnoyarsk, 660036, Russia
}

Received 25.09.2018, received in revised form 24.10.2018, accepted 29.10.2018

Effect of porous structure of carbon sorbents, obtained by alkaline thermal activation of ethanol-lignin of abies wood,on the methylene blue and the vitamin B12 sorption was studied. It was sown that their sorption capacity for vitamin B12 depends on the content of mesopores with width 2,00-3,61 nm and formethylene blue - on the content of micropores with width 1,06-1,95 $\mathrm{nm}$. The isotherms of sorption of the studied marker substances on sorbents with different porous structure were compared and their differences were discussed.

Keywords: ethanol-lignin, abies wood, alkaline activation, carbon sorbent, microproes, mesopores, isotherms of adsorption, methylene blue, vitamin $B_{12}$.

Citation: Veprikova E.V., Ivanov I.P., Chesnokov N.V., Kuznetsov B.N. Effect of a porous structure of the carbon sorbents from abies wood lignin on sorption of the organic substances of different nature, J. Sib. Fed. Univ. Chem., 2018, 11(4), 488-499. DOI: $10.17516 / 1998-2836-0093$.

\footnotetext{
(C) Siberian Federal University. All rights reserved

* Corresponding author E-mail address: veprikova2@mail.ru
} 


\title{
Влияние пористой структуры углеродных сорбентов \\ из лигнина древесины пихты \\ на сорбцию органических веществ различной природы
}

\author{
Е.В. Веприкова, И.П. Иванов, \\ Н.В. Чесноков, Б.Н. Кузнецов \\ Институт химии и химической технологии СО РАН \\ ФИЦ «Красноярский научный цуентр СО РАН» \\ Россия, 660036, Красноярск, Академгородок, 50/24
}

\begin{abstract}
Изучено влияние пористой структуры углеродных сорбентов, полученных щелочной термоактивацией этаноллигнина древесины пихты, на сорбцию метиленового синего и витамина $B_{12}$. Показано, что их сорбционная емкость по витамину $B_{12}$ зависит от содержания в них мезопор шириной 2,00 - 3,61 нм, а по метиленовому синему - от содержания микропор шириной 1,06 - 1,95 нм. Сопоставлены изотермы сорбции исследованных маркерных веществ на сорбентах с различной пористой структурой, обсуждены их отличия.
\end{abstract}

Ключевые слова: этаноллигнин, древесина пихты, щеелочная активация, углеродный сорбент, микропоры, мезопоры, изотермы адсорбции, метиленовый синий, витамин $B_{12}$.

\section{Введение}

Пористые материалы на основе органического и минерального сырья находят широкое применение в различных областях. Выбор исходного сырья и технологий получения позволяет создавать пористые материалы с различными параметрами структуры и степенью ее упорядоченности, соответствующие требованиям задачи, для решения которой предназначены эти материалы $[1,2]$. Соответствие параметров пористой структуры сорбентов размерам молекул извлекаемых веществ является решающим фактором эффективного проведения сорбционных процессов $[3,4]$. На основе параметров пористой структуры определяют возможность применения адсорбентов в хроматографии, в процессах сорбционного разделения и концентрирования и др. [2]. Известно, что от характера распределения пор по размерам зависит электрохимическое поведение активированных углей, предназначенных для получения электродных материалов. Микропоры в них должны быть доступны ионам электролитов и иметь средний диаметр не менее 1,0 нм. Необходимое условие достижения высокой электрической емкости - наличие в структуре активированных углей мезопор диаметром до 5,2 нм [5].

Перспективным направлением применения пористых материалов признаны процессы гемо- и энтеросорбции для удаления токсинов различной природы из биологических сред. Обзор литературы показал, что для гемосорбции более высокую эффективность при удалении высокомолекулярных токсинов проявляют материалы с развитой мезопористой структурой $[6$, 7]. В области энтеросорбции предпочтение отдается созданию сорбентов, содержащих в своей структуре поры разного размера, что позволяет удалять токсины разной природы (низко- и среднемолекулярные вещества, вещества белковой природы). Например, термическая пере-

$$
-489-
$$


работка косточкового сырья позволила получить углеродные сорбенты, в структуре которых присутствуют микропоры размером 1,2 - 1,6 нм. Наличие таких пор в сочетании с мезо- и макропорами обеспечивает возможность сорбции токсинов с крупными и разветвленными молекулами (белки, витамин $\mathrm{B}_{12}$, феназон, пептиды и др.) [8].

Перспективным направлением получения сорбентов с заданными характеристиками пористой структуры служит метод химической активации. Возможность варьирования параметров пористой структуры сорбентов в процессе их получения позволяет обеспечить соответствие свойств разработанных материалов конкретным задачам сорбционной очистки. Так, в работе [9] показаны возможности получения углеродных материалов на основе лигнина древесины пихты методом термохимической активации в присутствии гидроксида калия, позволяющие регулировать размеры и объемы микро- и мезопор в широких пределах.

При изучении свойств сорбентов медицинского назначения общепринятой практикой является применение маркерных веществ, моделирующих различные токсины: метиленовый синий моделирует токсины с массой до 500 Д; витамин $\mathrm{B}_{12}$, моделирующий токсины массой 500-1500 Д; желатин, который моделирует токсины белковой природы [10]. Исследования сорбции этих маркерных веществ позволили определить размеры микро- и мезопор, присутствие которых в структуре обеспечивает наибольшую эффективность сорбентов [11, 12]. Поскольку характер пористой структуры сорбентов, помимо условий получения, зависит и от природы исходного сырья, изучение влияния пор различного размера на сорбционные свойства вновь разработанного пористого материала считается актуальной задачей. Следует отметить, что такие исследования необходимы для оптимизации условий получения сорбента, предназначенного для применения в медицинских целях.

Цель работы заключалась в изучении влияния пористой структуры сорбентов, полученных термощелочной активацией лигнина древесины пихты при различных условиях, на их активность в сорбции метиленового синего и витамина $\mathrm{B}_{12}$.

\section{Экспериментальная часть}

Сырьем для получения углеродных сорбентов служил лигнин, выделенный из древесины пихты по методике [9]. Сорбенты были получены путем термохимической активации в присутствии КОН [9]. Условия получения сорбентов и их обозначения приведены в табл. 1.

Определение сорбционной активности сорбентов проводили по маркерным веществам с разной молекулярной массой: метиленовому синему (MC), моделирующему органические вещества с массой до 500 Д; витамину $\mathrm{B}_{12}$, моделирующему вещества массой 500-1500 Д. Сорбцию проводили из $0,15 \%$ раствора МС и $0,03 \%$ раствора витамина (рН растворов маркеров составлял $5,4)$ в соответствии с методикой [13]. Значения максимальной сорбции маркеров $\left(\mathrm{A}^{\text {мах }}\right)$ были получены при использовании навески сорбента, равной 10 мг. Изотермы сорбции МС и витамина $\mathrm{B}_{12}$ получали при постоянной исходной концентрации модельных растворов, варьируя массу навесок сорбента от 10 до 150 мг. Продолжительность сорбции составляла 1 ч. Процесс проводили при перемешивании на лабораторном приборе марки АВУ-6с (120 колеб/мин). Предварительно образцы углеродных сорбентов были измельчены до размера частиц менее 0,25 мм.

Концентрацию $\mathrm{MC}$ и витамина $\mathrm{B}_{12}$ измеряли спектрометрическим методом при длине волны 664 и 548 нм соответственно и толщине поглощающего слоя 1 см. 
Таблица 1. Условия получения углеродных сорбентов из лигнина древесины пихты

Table 1. Conditionsofobtainingofthecarbonsorbentsfromligninofabieswood

\begin{tabular}{|c|l|}
\hline $\begin{array}{c}\text { Образец } \\
\text { сорбента }\end{array}$ & \multicolumn{1}{|c|}{ Условия получения } \\
\hline ЭЛ-1 & Скорость нагрева $1{ }^{\circ} \mathrm{C} /$ мин, конечная температура $800{ }^{\circ} \mathrm{C}$, выдержка при $800{ }^{\circ} \mathrm{C} 1$ ч \\
\hline ЭЛ-2 & Скорость нагрева $5{ }^{\circ} \mathrm{C} /$ мин, конечная температура $800{ }^{\circ} \mathrm{C}$. выдержка при $800{ }^{\circ} \mathrm{C} 1$ ч \\
\hline ЭЛ-3 & Скорость нагрева $10^{\circ} \mathrm{C} /$ мин, конечная температура $800{ }^{\circ} \mathrm{C}$, аргон \\
\hline ЭЛ-4 & Скорость нагрева $20^{\circ} \mathrm{C} /$ мин, конечная температура $800{ }^{\circ} \mathrm{C}$, выдержка при $800{ }^{\circ} \mathrm{C} 1$ ч \\
\hline ЭЛ-5 & Скорость нагрева $40^{\circ} \mathrm{C} /$ мин, конечная температура $800{ }^{\circ} \mathrm{C}$, выдержка при $800{ }^{\circ} \mathrm{C} 1$ ч \\
\hline ЭЛ-6 & Скорость нагрева $10^{\circ} \mathrm{C} /$ мин, выдержка при $350{ }^{\circ} \mathrm{C}-30$ мин, выдержка при $800{ }^{\circ} \mathrm{C}-1$ ч \\
\hline ЭЛ-7 & Скорость нагрева $10^{\circ} \mathrm{C} /$ мин, выдержка при $450{ }^{\circ} \mathrm{C}-30$ мин, выдержка при $800{ }^{\circ} \mathrm{C}-1$ ч \\
\hline ЭЛ- 8 & Скорость нагрева $10^{\circ} \mathrm{C} /$ мин, выдержка при $550{ }^{\circ} \mathrm{C}-30$ мин, выдержка при $800{ }^{\circ} \mathrm{C}-1$ ч \\
\hline ЭЛ-9 & Скорость нагрева $10^{\circ} \mathrm{C} /$ мин, выдержка при $650{ }^{\circ} \mathrm{C}-30$ мин, выдержка при $800{ }^{\circ} \mathrm{C}-1$ ч \\
\hline
\end{tabular}

Для обработки данных по сорбции использовали уравнения Ленгмюра (1) и Фрейндлиха (2), приведенные к линейному виду:

$$
\begin{aligned}
& \mathrm{A}^{-1}=\left(\mathrm{A}_{\infty} \mathrm{K}_{\mathrm{L}}\right)^{-1} \mathrm{C}_{\mathrm{p}}^{-1}+\mathrm{A}_{\infty}^{-1}, \\
& \log \mathrm{A}=\log \mathrm{K}_{\mathrm{F}}+\mathrm{n}^{-1} \log \mathrm{C}_{\mathrm{p}},
\end{aligned}
$$

где А - сорбция маркера, мг/г; $\mathrm{A}_{\infty}$ - предельная сорбция маркера, мг/г; $\mathrm{C}_{\mathrm{p}}$ - равновесная концентрация маркера, мг/л; $\mathrm{K}_{\mathrm{L}}$ - константа уравнения Ленгмюра; $\mathrm{K}_{\mathrm{F}}-$ константа уравнения Фрейндлиха; $\mathrm{n}$ - константа интенсивности сорбции в уравнении Фрейндлиха.

На основе этих уравнений вычисляли соответствующие коэффициенты для сорбции МС и витамина $\mathrm{B}_{12}$.

Графический анализ зависимостей сорбционной емкости сорбентов по МС и витамину $\mathrm{B}_{12}$ проводили с помощью программы OriginPro 8.

Характеристики пористой структуры углеродных сорбентов определены по изотермам низкотемпературной адсорбции азота (чистотой 99,999 \%) при температуре 77,4 К, измеренным на объемной вакуумной статической установке ASAP 2029MP-C, Micromeritics. Диапазон равновесных относительных давлений составлял от $10^{-7}$ до $0,994 \mathrm{P} / \mathrm{P}_{\mathrm{o}}$. Перед проведением анализа образцы вакуумировали при $300{ }^{\circ} \mathrm{C}$ в течение 12 ч.

Определение объемов микро- и мезопор сорбентов выполняли с помощью сравнительного t-метода с использованием уравнения Hurkins-Jura для расчета толщины статистического слоя адсорбата [14]. Распределение пор по размеру было рассчитано с помощью метода теории функционала плотности NLDFT (density functional theory) [15].

\section{Результаты и обсуждение}

Результаты определения объема пор разного размера в углеродных сорбентах из лигнина древесины пихты приведены в табл. 2.

$$
-491-
$$


Таблица 2. Влияние размера и объема пор на сорбционные свойства углеродных сорбентов из лигнина древесины пихты (ЭЛ)

Table 2. Effect of pores size andits volume on the sorption properties of carbon sorbents from lignin of abies wood (ЭЛ)

\begin{tabular}{|c|c|c|c|c|c|c|c|c|c|}
\hline \multirow[b]{2}{*}{ Образец } & \multicolumn{7}{|c|}{ Объем пор различной ширины, см³/Г } & \multicolumn{2}{|c|}{$\mathrm{A}^{\text {мах }}, \mathrm{M \Gamma} / \Gamma$} \\
\hline & $\begin{array}{c}0,49- \\
0,80 \text { нм }\end{array}$ & $\begin{array}{c}0,83- \\
1,03 \text { нм }\end{array}$ & $\begin{array}{c}1,06- \\
1,38 \text { нм }\end{array}$ & $\begin{array}{c}1,43- \\
1,63 \mathrm{нм}\end{array}$ & $\begin{array}{c}1,69- \\
1,95 \text { нм }\end{array}$ & $\begin{array}{c}2,00- \\
2,24 \text { нм }\end{array}$ & $\begin{array}{c}2,32- \\
3,61 \mathrm{нм}\end{array}$ & $\mathrm{MC}$ & $\mathrm{B}_{12}$ \\
\hline ЭЛ-1 & 0,46 & 0,02 & 0,17 & 0,12 & 0,17 & 0 & 0 & 496,79 & 25,15 \\
\hline ЭЛ-2 & 0,45 & 0 & 0,24 & 0,19 & 0,27 & 0,07 & 0,14 & 1067,06 & 52,74 \\
\hline ЭЛ-3 & 0,40 & 0 & 0,23 & 0,17 & 0,21 & 0,15 & 0 & 1079,11 & 65,18 \\
\hline ЭЛ-4 & 0,39 & 0 & 0,22 & 0,14 & 0,25 & 0 & 0,53 & 934,55 & 141,97 \\
\hline ЭЛ-5 & 0,32 & 0 & 0,23 & 0,14 & 0,27 & 0 & 0,82 & 1075,29 & 188,18 \\
\hline ЭЛ-6 & 0,37 & 0 & 0,25 & 0,17 & 0,18 & 0,21 & 0,01 & 927,09 & 52,29 \\
\hline ЭЛ-7 & 0,37 & 0,01 & 0,17 & 0,10 & 0,11 & 0,07 & 0 & 673,87 & 44,49 \\
\hline ЭЛ-8 & 0,35 & 0,01 & 0,17 & 0,10 & 0,07 & 0 & 0 & 384,69 & 22,86 \\
\hline ЭЛ-9 & 0,35 & 0,01 & 0,20 & 0,14 & 0,17 & 0,04 & 0 & 647,71 & 32,36 \\
\hline УA-H* & 0,11 & 0,0 & 0,05 & 0,01 & 0 & 0 & 0,01 & 256,96 & 61,36 \\
\hline
\end{tabular}

* Образец сравнения - УА-Н (уголь активированный, г. Новосибирск); ${ }^{\text {мах }}$ - максимальная сорбция маркеров; МС метиленовый синий, $\mathrm{B}_{12}-$ витамин $\mathrm{B}_{12}$.

Сорбенты ЭЛ - 1 и ЭЛ - 8 не содержат в своей структуре пор размером более 2,0 нм. Максимальная ширина микропор для этих сорбентов не превышает 1,95 и 1,81 нм соответственно. В структуре сорбентов ЭЛ - 3, ЭЛ - 6, ЭЛ - 7 и ЭЛ - 9 присутствуют мезопоры размером $2,0-2,24$ нм. Для образца ЭЛ - 6 характерно наличие небольшого количества более крупных пор размером до 3,61 нм. Сорбенты ЭЛ - 4 и ЭЛ -5 отличаются присутствием в их структуре крупных мезопор $(2,32-3,61$ нм) и отсутствием пор размером 2,00 - 2,24 нм. Пористая структура ЭЛ-2 содержит, в отличие от остальных сорбентов из лигнина, мезопоры разного размера. Различия в пористой структуре полученных сорбентов обуславливают различия в их сорбционной активности в отношении витамина $\mathrm{B}_{12}$ и МС (табл. 2).

Известно, что молекула витамина $\mathrm{B}_{12}$ имеет следующие размеры - 1,41 х 1,83 х 1,14 нм [16]. Поэтому к доступным для ее адсорбции можно отнести поры диаметром более 1,41 нм. При этом для эффективной сорбции сорбент должен иметь также транспортные поры диаметром от 2,4 до 3,2 нм [12]. В структуре сорбентов ЭЛ - 1 и ЭЛ - 8 на долю пор, доступных для молекул $\mathrm{B}_{12}$ (поры шириной от 1,43 до 1,95 нм), приходится 30,9 и 24,3 \% от общего объема. Однако максимальная ширина пор в этих сорбентах не превышает 1,95 нм. В связи с этим они демонстрируют наименьшую сорбционную емкость по витамину $\mathrm{B}_{12}$ в сравнении с другими сорбентами.

Появление в структуре сорбентов более крупных пор (от 2,00 до 2,24 нм) приводит к увеличению сорбции витамина $\mathrm{B}_{12}$. В зависимости от условий получения сорбентов на долю этих пор приходится от 4,4 до 18,6 \%. Можно предположить, что присутствующие мезопоры способствуют транспорту молекул $\mathrm{B}_{12}$ к более мелким сорбирующим порам. Сравнение свойств сорбентов из лигнина демонстрирует тенденцию увеличения сорбции маркерного вещества по мере увеличения в них объема пор указанного размера. Однако повышение количества мезопор в 3 раза, наблюдаемое для сорбента ЭЛ - 6 по сравнению с ЭЛ - 7, не приводит к суще- 
ственному повышению сорбции витамина $\mathrm{B}_{12}$. Сорбент ЭЛ - 6 по количеству мезопор $\geq 2,0$ нм превосходит сорбент ЭЛ - 3, но характеризуется меньшей сорбцией витамина $\mathrm{B}_{12}$ (табл. 2). Это может свидетельствовать о том, что сорбенты, полученные при разных условиях, могут отличаться не только соотношением объемов микро- и мезопор, а также природой и количеством активных центров, образующихся на поверхности сорбентов.

Сравнение сорбции витамина $\mathrm{B}_{12}$ сорбентами ЭЛ - 7 и ЭЛ - 2 определило, что появление в структуре последнего мезопор размером $2,32-3,61$ нм в объеме $0,14 \mathrm{~cm}^{3} / \Gamma$ недостаточно для существенного увеличения поглощения данного маркера. Как показывают данные табл. 2, на долю мезопор такого размера в структуре сорбентов ЭЛ - 4 и ЭЛ - 5 приходится 34,6 и 46,1 \% от общего объема пор сорбентов и 57,6 и 66,7 \% от объема пор, доступных для сорбции витамина $\mathrm{B}_{12}$, соответственно. Это сопровождается увеличением сорбции витамина $\mathrm{B}_{12}$ на них в 2,7 и 3,6 раза по сравнению с ЭЛ - 2 соответственно. Также для сорбентов ЭЛ - 4 и ЭЛ - 5 выявлены различия в распределении мезопор вышеуказанного размера (рис. 1).

Структура ЭЛ - 5 характеризуется не только большим объемом мезопор, но и присутствием пор с максимальной шириной 3,26 нм. Средняя ширина мезопор для сорбентов ЭЛ - 4 и ЭЛ - 5 составляет 2,76 и 3,01 нм соответственно. Таким образом, увеличение ширины мезопор и их объема в структуре сорбента приводит к увеличению сорбции витамина $\mathrm{B}_{12}$.

Сорбенты из лигнина, за исключением ЭЛ - 3, ЭЛ - 4 и ЭЛ - 5, уступают по сорбции витамина $\mathrm{B}_{12}$ активированному углю УА-Н, выбранному в качестве образца сравнения. Очевидно, размеры мезопор, присутствующих в этих сорбентах, и их количество недостаточны для эффективной сорбции $\mathrm{B}_{12}$.

Наглядно это подтверждает сравнение распределения пор по размерам для сорбентов ЭЛ - 6 и УА-Н (рис. 2). Отличительной особенностью образца сравнения является отсутствие в его структуре пор шириной от 1,81 до 3,04 нм. При этом отмечено наличие мезопор шириной $3,27,5,09,5,87$ и 7,47 нм. Доля мезопор в общем объеме пор сорбента составляет $35,9 \%$. На долю микропор, по своим размерам доступных молекулам витамина $\mathrm{B}_{12}$, в структуре УА-Н приходится 2,6 \%. В структуре сорбентов из лигнина древесины пихты эти поры, в зависимости от условий получения, занимают от 24,3 до $34,1 \%$. Очевидно, для достижения эффективной

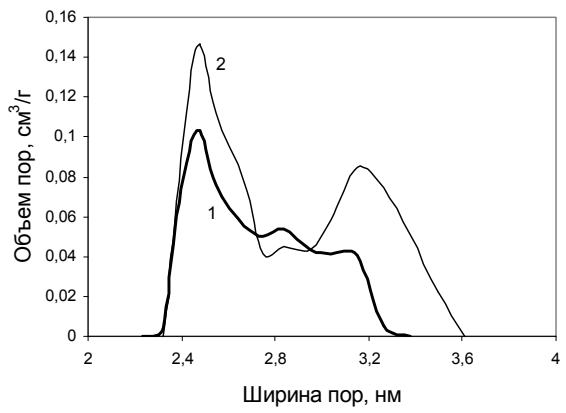

Рис. 1. Распределение мезопор по размерам для сорбентов из лигнина ЭЛ - 4 (1) и ЭЛ - 5 (2)

Fig. 1. Mesopores size distribution for the sorbents from lignin ЭЛ - 4 (1) and ЭЛ - 5 (2)

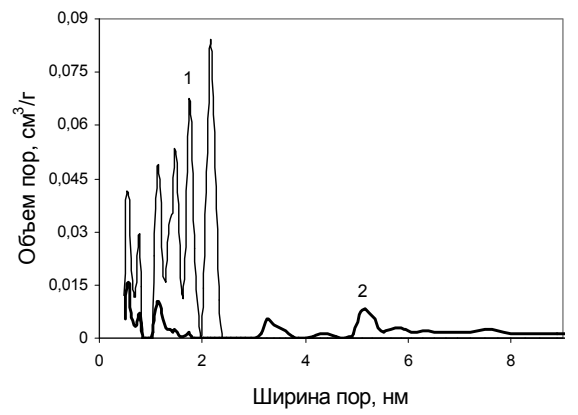

Рис. 2. Распределение пор по размерам для сорбента из лигнина ЭЛ - 6 (1) и активного угля УА-Н (2)

Fig. 2. Pores size distribution for the sorbent from lignin ЭЛ - 6 (1) and active coal УА-Н (2) 
сорбции витамина $\mathrm{B}_{12}$ сорбент должен обладать оптимальным сочетанием объема микро- и мезопор, которое наблюдается для сорбентов из лигнина ЭЛ - 4 и ЭЛ - 5.

Приведенные в табл. 2 данные показывают, что сорбенты ЭЛ - 4 и ЭЛ - 5 по своей сорбционной емкости превосходят образец сравнения УА-Н в 2,3 и 3,1 раза. Сравнение их структурных характеристик и значений сорбции витамина $\mathrm{B}_{12}$ позволяет предположить, что определяющее значение для более эффективной сорбции имеет количество мезопор размером до 3,61 нм, а присутствие пор более 3,61 нм не является необходимым условием.

Доступными для метиленового синего (МС), имеющего размер молекул 0,47 х 0,84 х 1,60 нм [12], можно считать поры шириной более 0,84 нм. Установлено, что по своей сорбционной емкости в отношении МС полученные из лигнина сорбенты превосходят образец сравнения УА-Н. Данный факт может быть обусловлен менее развитой пористой структурой УА-Н (табл. 2).

Появление в структуре углеродных сорбентов из лигнина мезопор шириной 2,00-2,24 нм приводит к существенному увеличению сорбции МС. Вероятно, мезопоры, помимо сорбции, выполняют транспортную функцию, что позитивно влияет на сорбционную активность сорбентов. Но, как показывают данные табл. 2, появление пор шириной 2,32 - 3,61 нм в сорбентах ЭЛ -4 и ЭЛ - 5 и существенное повышение их объема (в 1,5 раза) не приводят к значительному увеличению сорбции МС в отличие от сорбции витамина $\mathrm{B}_{12}$.

Увеличение объема микропор шириной $1,06-1,95$ в сорбентах ЭЛ - 8 и ЭЛ - 9 от 0,34 до $0,51 \mathrm{~cm}^{3} / \Gamma$ сопровождается увеличением их емкости по МС в 1,7 раза. Высокими значениями сорбции МС (более 927,09 мг/г) характеризуются сорбенты ЭЛ - 2, ЭЛ - 3, ЭЛ - 4, ЭЛ - 5 и ЭЛ -6 , содержащие в своей структуре от 0,60 до $0,70 \mathrm{~cm}^{3} / \Gamma$ пор такого размера. Для этих сорбентов повышение объема доступных молекулам МС микропор дополняется появлением мезопор разного размера. Однако в ряде случаев увеличение размера и количества мезопор не приводит к увеличению сорбционной емкости сорбентов. Очевидно, что величина сорбции МС определяется в большей степени количеством микропор, по своим размерам доступных для молекул данного маркерного вещества. Это подтверждают и результаты сравнения значений сорбционной емкости сорбентов из лигнина и образца сравнения (табл. 2).

На примере сорбента ЭЛ - 3 установлено, что для достижения высокого значения сорбционной емкости по МС достаточным условием является наличие мезопор шириной 2,00-2,24 нм в количестве $0,15 \mathrm{~cm}^{3} / \Gamma$ (табл. 2).

Изучение взаимосвязи сорбционной емкости сорбентов из лигнина по витамину $\mathrm{B}_{12}$ от объема микро- и мезопор, доступных для его молекул, показывает, что она описывается линейной зависимостью (рис. 3).

При этом наибольшее значение коэффициента аппроксимации было получено, когда в качестве доступных были выбраны поры шириной от 1,69 до 3,61 нм. С учетом влияния на сорбцию витамина $\mathrm{B}_{12}$ микропор размером 1,43 - 1,63 нм была также получена линейная зависимость, но с меньшим коэффициентом аппроксимации. Сорбция данного маркера линейным образом зависит и от объема мезопор, присутствующих в структуре сорбентов из лигнина (табл. 3).

Зависимость сорбции МС от общего объема доступных микро- и мезопор имеет более сложный характер и за исключением точек, соответствующих сорбентам ЭЛ - 2 и ЭЛ - 3, аппроксимируется полиномиальным уравнением (рис. 3). Аналогичными уравнениями описывается влияние объема микропор, доступных МC, и мезопор на сорбцию этого маркерного 


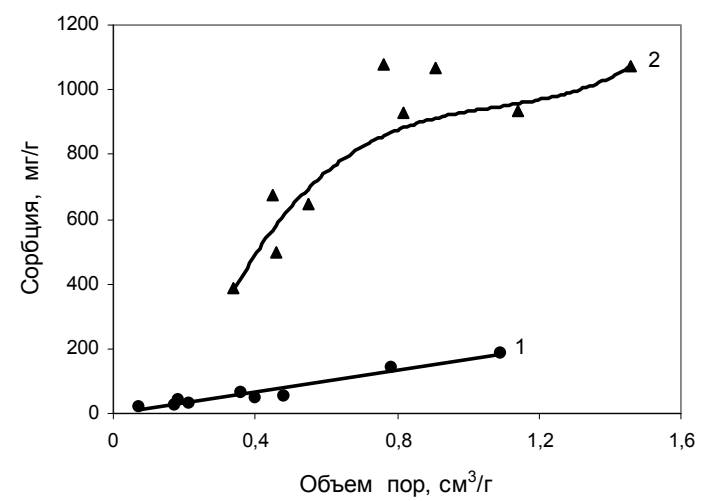

Рис. 3. Зависимость сорбции витамина $\mathrm{B}_{12}$ (1) и метиленового синего (2) от объема пор сорбентов из лигнина: 1 - от объема пор шириной 1,69 - 3,61 нм; 2 - от объема пор шириной 1,06 - 3,61 нм

Fig. 3. Dependence of vitamin $B_{12}(1)$ and methylene blue (2) sorption on the pores volume of the sorbents from lignin: 1 - on volume of the pores width $1,69-3,61 \mathrm{~nm} ; 2$ - on volume of the pores width 1,06-3,61 nm

Таблица 3. Результаты аппроксимации зависимости сорбции витамина $\mathrm{B}_{12}$ и метиленового синего (МС) от объема пор разного размера в сорбентах из лигнина

Table 3. The results of approximation of sorption dependence of vitamin $\mathrm{B}_{12}$ and methylene blue (MC) on volume of pores with different size in sorbents from lignin

\begin{tabular}{|c|c|c|}
\hline Ширина пор, доступных маркеру, нм & Уравнение & $\mathrm{R}^{2}$ \\
\hline \multicolumn{2}{|c|}{ Сорбция витамина $\mathrm{B}_{12}$} & 0,942 \\
\hline $1,69-3,61$ & $\mathrm{~A}_{\mathrm{B} 12}=167,79 \mathrm{~V}-0,2559$ & 0,903 \\
\hline $1,43-3,61$ & $\mathrm{~A}_{\mathrm{B} 12}=158,34 \mathrm{~V}-18,675$ & 0,972 \\
\hline $2,00-3,61$ & $\mathrm{~A}_{\mathrm{B} 12}=204,26 \mathrm{~V}+23,354$ & 0,939 \\
\hline & Сорбция MC & 0,839 \\
\hline $1,06-3,61$ & $\mathrm{~A}_{\mathrm{MC}}=1075,4 \mathrm{~V}^{3}-3487,4 \mathrm{~V}^{2}-3940,9 \mathrm{~V}-596,42$ & 0,975 \\
\hline
\end{tabular}

* $\mathrm{A}_{\mathrm{B} 12}$ - сорбция витамина $\mathrm{B}_{12}, \mathrm{Mг} / \Gamma ; \mathrm{A}_{\mathrm{MC}}-$ сорбция метиленового синего, мг/г; $\mathrm{V}$ - объем пор, $\mathrm{cm}^{3} / \Gamma ; \mathrm{R}^{2}-$ коэффициент аппроксимации.

вещества (табл. 3). Низкое значение $\mathrm{R}^{2}$, полученное при оценке влияния объема микропор на сорбцию MC, указывает на необходимость учитывать вклад мезопор.

Сложный характер полученных зависимостей позволяет предположить, что сорбция МС может зависеть не только от параметров пористой структуры сорбентов. Определенное влияние на сорбцию может оказывать и химическое состояние поверхности сорбентов, определяемое условиями их получения. Следует учитывать, что МС является типичным катионным красителем и его взаимодействие с заряженными центрами на поверхности сорбента будет приводить к увеличению сорбции или затруднять ее [17].

Для углеродных сорбентов ЭЛ - 5 и ЭЛ - 8, существенно различающихся характером пористой структуры, была изучена сорбция витамина $\mathrm{B}_{12}$ и $\mathrm{MC}$ в широком интервале их концен- 
траций. Изотерму сорбции витамина $\mathrm{B}_{12}$, полученную для ЭЛ - 5 , отличает наличие крутого подъема в области низких равновесных концентраций до 5,88 мг/г (рис. 4).

Для ЭЛ - 5 сорбция исследуемого маркера достоверно аппроксимируется уравнением Фрейндлиха $\left(\mathrm{R}^{2}=0,966\right)$ (рис. 4, кривая 1). Изотерма сорбции $\mathrm{B}_{12}$ сорбентом ЭЛ -8 с высокой степенью аппроксимации описывается уравнением Ленгмюра $\left(\mathrm{R}^{2}=0,987\right)$ (рис. 4 , кривая 2$)$. Для этого сорбента экспериментальное значение $\mathrm{A}_{\max }(22,86$ мг/г) близко к расчетному значению предельной сорбции $\mathrm{A}_{\infty}(27,07$ мг/г), что указывает на высокую степень заполнения адсорбционного слоя.

Характер изотерм сорбции МС на этих сорбентов существенно различается (рис. $5 a, \sigma)$. Так, изотерма для ЭЛ - 5 с высокой степенью аппроксимации описывается уравнением Фрейндлиха $\left(\mathrm{R}^{2}=0,989\right)$. В процессе сорбции МС сорбентом ЭЛ - 8 в области равновесных концентра-

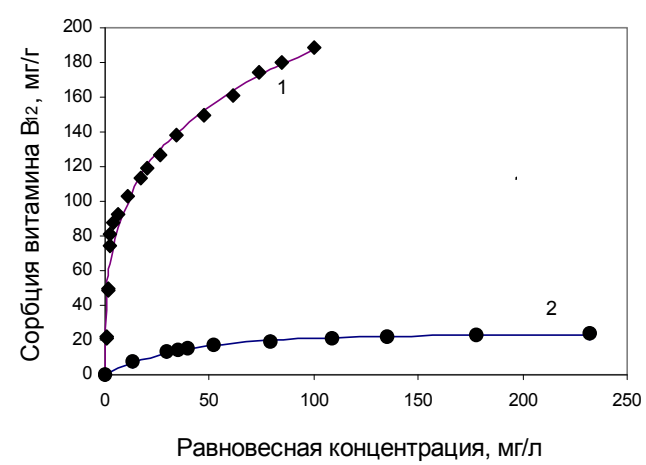

Рис. 4. Изотермы сорбции витамина $\mathrm{B}_{12}$ для углеродных сорбентов из лигнина ЭЛ - 5 (1) и ЭЛ - 8 (2): точки - экспериментальные значения; линии - результаты расчета по уравнениям Фрейндлиха (1) и Ленгмюра (2)

Fig. 4. Isotherms of vitamin $B_{12}$ sorption for carbon sorbents from lignin ЭЛ - 5 (1) and ЭЛ - 8 (2): points - the experimental dates, lines - the results of calculation by the equation of Freundlich (1) and Langmuir (2)

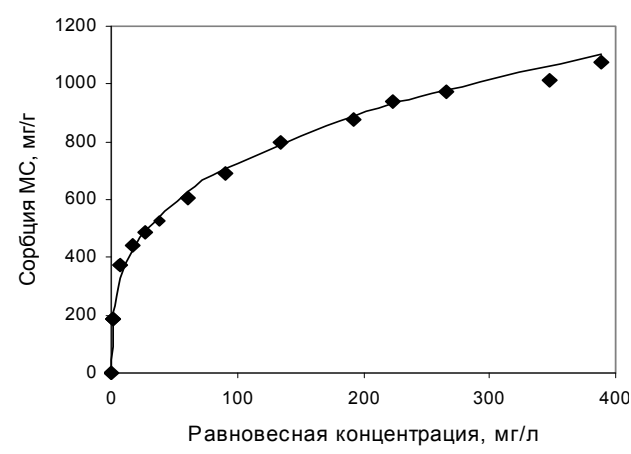

a

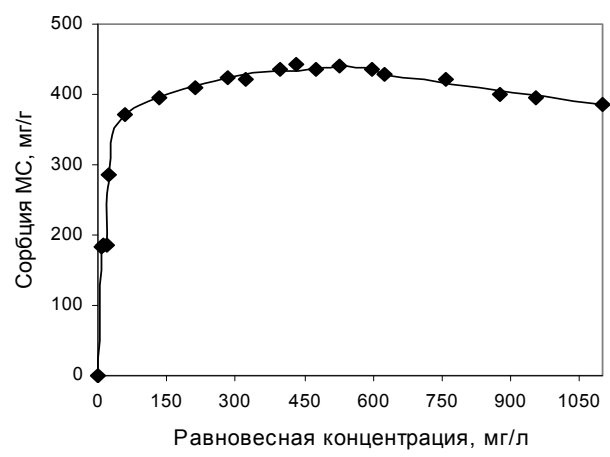

6

Рис. 5. Изотермы сорбции метиленового синего (МС) для углеродных сорбентов из лигнина ЭЛ - 5 (a) и ЭЛ - 8 (б): точки - экспериментальные значения; линия на рис. $5 a$ - результаты расчета по уравнению Фрейндлиха

Fig. 5. Isotherms of methylene blue (MC) sorption for carbon sorbents from lignin ЭЛ - 5 (а) and ЭЛ - 8 (б): points - the experimental dates, line on the Fig. $5 a$ - the results of calculation by the equation of Freundlich 
ций маркера от 476 до 596 мг/л достигается его максимальная сорбция (439,48 мг/г). Дальнейшее увеличение равновесной концентрации МС до 1099,76 мг/л сопровождается уменьшением сорбции до 384,69 мг/г (рис. 56).

Уменьшение сорбционной емкости образца ЭЛ -8 с ростом равновесной концентрации маркера может быть вызвано переориентацией молекул МС в адсорбционном слое. Известно, что при вертикальной ориентации одна молекула $\mathrm{MC}$ занимает площадь 0,64 нм² $^{2}$ а в случае плоской ориентации - около 1,20 нм². Из водных растворов МС сорбируется в виде димеров, что не влияет на занимаемую площадь поверхности при условии плоской ориентации агрегатов. Причиной сорбционного максимума на изотерме может быть и присутствие на поверхности сорбента кислородсодержащих центров сорбции, способных ионизироваться при высоких равновесных концентрациях маркерного вещества [17].

\section{Заключение}

Изучено влияние размера и количества пор, присутствующих в структуре углеродных сорбентов из лигнина древесины пихты, на сорбцию метиленового синего и витамина $\mathrm{B}_{12}$. Выявлено различное влияние микро- и мезопор на сорбционную емкость сорбентов в зависимости от природы маркерного вещества. Показано, что к увеличению сорбции витамина $\mathrm{B}_{12}$ приводит появление в структуре сорбентов мезопор. Наибольшую сорбцию данного маркера (не менее 141,97 мг/г) демонстрируют сорбенты, содержащие мезопоры шириной 2,32 - 3,61 нм.

Установлено, что сорбционная емкость по метиленовому синему изученных сорбентов определяется содержанием в их структуре микропор шириной 1,06-1,95 нм, причем для достижения высокой сорбции данного маркера в структуре сорбента также должны присутствовать мезопоры шириной 2,00-2,24 нм.

Показано, что углеродные сорбенты из лигнина древесины пихты превосходят образец промышленного активированного угля по сорбционной емкости в отношении метиленового синего в 2,3-3,1 и витамина $\mathrm{B}_{12}$ в 3,6-4,2 раза.

\section{Список литературы}

1. Карпов С.И., Roessner F., Селеменев В.Ф., Гульбин С.С., Беланова Н.А., Бородина Е.В., Корабельникова Е.О., Крижановская О.О., Недосекина И.В. Перспективы синтеза и использования упорядоченных мезопористых материалов при сорбционно-хроматографическом анализе, разделении и концентрировании физиологически активных веществ (Обзор). Сорбционные и хроматографические процессы 2013. Т. 13(2), С. 125 - 140. [Karpov S.I., Roessner F., Selemenev V.F., Gulbin S.S., Belanova N.A., Borodina E.V., Korabelnikova E.O., Krizhanovskaya O.O., Nedosekina I.V. Prospects of synthesis and applications of high ordered mesoporous materials as a sorbents for chromatographic analysis, separation and preconcentration of physiologically active substances (Review). Sorption and Chromatographic Processes 2013. Vol. 13(2), P. 125 - 140. (in Russ.)]

2. Mukhin V.M., Burakov A.Ye., Burakova I.V. Active carbon as nanoporous material for solving environmental problems. Advanced materials and technologies 2017. No. 2, P. 50 - 56.

3. Tarkovslaya I.A. et al. Effect of the porous structure parameters of carbon materials on the sorption of platinum chloride complexes. Theoretical and experimental Chemistry 1999. Vol. 35(4), P. $225-230$. 
4. Киселева Е.А., Раздьяконова Г.И., Неделькин В.И. Влияние размера микропор углеродной поверхности на сорбцию эластомеров. Каучук и резина 2010. № 4, С. 42 - 43. [Kiseleva Е.А., Razdyakonova G.I., Nedelkin V.I. Effect of microspores sizes of carbon surface on a elastomers sorbtion. Journal Kauchuk and Rezina 2010. No. 4, P. 42 - 43. (in Russ.)]

5. Жен Х.Я., Ю А.М., Ма К.А. Влияние характеристик пор на электрохимическую емкость активированных углей. Электрохимия 2012. Т. 48(12), С. 1294 - 1302. [Zheng H.J., Yu A.M., Ma K.A. Effect of pores characteristics on the electrochemical capacity of active coals. Electrochemistry 2012. Vol. 48(12), P. 1294 - 1302. (in Russ.)]

6. Kaznacheiva N.M. et al. Role of the porous structure of the hemosorbent in the sorption of large molecules. Pharmaceutical Chemistry Journal 1987. Vol. 21 (2), P. 149 - 152.

7. Пьянова Л.Г., Лихолобов В.А., Долгих Т.И., Соколова Т.Ф., Долгих В.Т., Лузянина Л.С., Филиппов С.И., Глущенко А.В., Ершов А.В. Изучение сорбции цитокинов на поверхности модифицированного углеродного сорбента. Эфферентная терапия 2010. Т. 16(1), С. 16-19. [Pyanova L.G., Lixolobov V.A, Dolgix T.I., Sokolova T.F., Dolgix V.T., Luzyanina L.S., Filippov S.I., Gluchenko A.V., Ershov A.V. Study of zitoksines sorption on the surface of modified carbon sorbent. Journal Efferent Therapy 2010. Vol. 16(1), P. 16-19. (in Russ.)]

8. Патент 2377179 РФ. Мухин В.М., Жуков Д.С., Зубова И.Д., Чебыкин В.В., Чумаков Д.С., Соловьев С.М., Курганов Р.П. Углеродный адсорбент, способ получения и установка для его осуществления. Опубл. 27.12.2009. [Patent 2377179 RU. Muxin V.M., Gukov D.S., Zubov I.D., Chebykin V.V., Chumakov D.S., Solovev S.M., Kurganov R.P. Carbon adsorbent, method of its preparations and installation for him obtaining. Publ. Date 27.12.2009. (in Russ.)]

9. Иванов И.П., Микова Н.М., Лутошкин М.А., Чесноков Н.В., Кузнецов Б.Н. Изучение строения и свойств нанопористых углеродных материалов, полученных термощелочной активацией лигнинов древесины пихты. Журнал Сибирского федерального университета. Химия 2017. T. 10(3), C. 390-400. [Ivanov I.P., Mikova N.M., Lutoshkin M.A., Chesnokov N.V., Kuznetsov B.N. The study of structure and properties of nanoporous carbon materials obtained by alkaline thermal activation of lignin of Fir wood. Journal of Siberian federal University. Chemistry 2017. Vol. 10(3), P. 390-400. (in Russ.)]

10. Reshetnikov V.I. Evaluation of the adsorption capacity of enterosorbents and related medicinal preparations. Pharmaceutical Chemistry Journal 2003. Vol. 37(5), P. 246 - 251.

11. Фарберова Е.А., Олонцев В.Ф., Тингаева Е.А. Исследование условий получения активных углей медицинского назначения из косточек плодов. Бутлеровские сообщения 2016. T. 47(8), C. 73 - 79. [Farberova E.A., Olontsev V.F., Tingaeva E.A. Investigation of the conditions for obtaining active carbons medical supplies from seed fruit. Butlerov communications 2016 .Vol. 47(8), P. 73 - 79 (in Russ.)]

12. Морозова А.А., Лыга Л.К., Ермоленко И.Н. О роли микро- и мезопор волокнистых активных углей в сорбции веществ маркеровиз водных сред. Журнал прикладной химии 1989. № 12, C. 2777 - 2781. [Morozova A.A., Lyga L.K., Ermolenko I.N. About rule of micro- and mezopores fiber active carbon in sorption of marker substances from water medium. Journal of Applied Chemistry 1989. No. 12, P. 2777 - 2781. (in Russ.)]

13. Markelov D.A., Nitsak O.V., Gerashenko T.T. Comparative study of the adsorption activity of medicinal sorbents. Pharmaceutical Chemistry Journal 2008. Vol. 42(7), P. 405 - 408. 
14. Scherdel C., Reichenauer G., Wiener M. Relationship between pore volumes and surface areas derived from the evaluation of $\mathrm{N}_{2}$-sorption data by DR-, BET- and t-plot. Microporous and Mesoporous Materials 2010. Vol. 132(3), P. 572-575.

15. Landers J., Gor G. Yu., Neimark A.V. Density functional theory methods for characterization of porous materials. Colloids and Surfaces A: Physicochemical and Engineering Aspects 2013. Vol. 437, P. 3-32.

16. Yao Chen. Synthesis, characterization and mechanistic studies of Biomolecules@ mesoMOFs. URL: Http://scholarcommons.ust.edu/etd/5199 (22.05.2018).

17. Адсорбция из растворов на поверхности твердых тел: пер. с англ. под ред. Г. Парфита, К. Рочестера. М.: Мир, 1986. 488 с. [Adsorption from solution at the solid/liquid interface: trans. from english. Editted by Parfitt G.D., Rochester C.H. M: Mir, 1986. 488 p. (in Russ.)] 